\title{
Prevalence of psychiatric symptoms in children and adolescents one year after the 2009 L'Aquila earthquake
}

\author{
Paolo Feo ${ }^{1}$, Simona Di Gioia', Emanuela Carloni ${ }^{1}$, Benedetto Vitiello ${ }^{3}$, Alberto Eugenio Tozzi ${ }^{2}$ and Stefano Vicari ${ }^{*}$
}

\begin{abstract}
Background: In 2009, an earthquake devastated the Abruzzo region in Italy. Despite the occurrence of several disasters in this country, no study on mental health of Italian children has ever been conducted in complex emergencies. Objective of the study was to assess the prevalence of psychiatric symptoms among children in the affected area 12 to 17 months after the event.

Methods: A community sample of 1839 3-14 years children was identified from the general population assigned to 37 paediatricians of the National Health System, including children living in the earthquake epicentre, the surrounding earthquake zone, and the adjacent non-affected areas. Psychiatric symptoms were assessed with the Child Behavior Checklist (CBCL) and the Youth Self Report (YSR), completed by 452 children aged 11-14 years. The association between symptoms and sociodemographic, health, family, and earthquake-related factors was examined.

Results: The prevalence of CBCL-defined cases was $14.9 \%$ in the epicentre, $13.0 \%$ in the remainder earthquake zone, $13.9 \%$ in the unaffected area $(p=.876)$. No differences among areas were found when comparing the YSR results. Prevalence of CBCL-defined post-traumatic stress (PTS) cases was $8.4 \%$ in the epicentre, $4.0 \%$ in the remainder earthquake zone, $2.2 \%$ in the unaffected area $(p=.002)$. PTS and anxiety were significantly more frequent in the epicentre than in other areas only in the 6-10 year-old children group (respectively $p=.009$ and $p=.014)$. In multivariate logistic analyses, factors associated with PTS were living in the epicentre $(O R=3.6)$ and child or maternal history of mental health care prior to the earthquake (respectively $O R=7.1$ and $O R=4.5$ ).

Conclusions: Children living in the epicentre, particularly those 6-10 years old, had the highest prevalence of CBCL-defined cases, and of PTS and anxiety symptoms one year after the earthquake. No signs of increased psychopathology were detected in younger (3-5 years) or older children (11-14 years). Family and health related factors showed stronger association with psychiatric outcomes than earthquake-related factors. The identification of populations at higher risk of developing psychiatric symptoms has implications for public health interventions in complex emergencies.
\end{abstract}

Keywords: Abruzzo, Child and adolescent, Mental health, CBCL, Post traumatic stress disorder

\section{Background}

On April 6, 2009 an earthquake measuring 5.9 on the Richter scale hit the city of L'Aquila and the surrounding area in the Abruzzo Region, Italy. The event affected 57 municipalities, killed 308 persons, injured more than 1,600 people and displaced more than 67,000 people. It

\footnotetext{
*Correspondence: stefano.vicari@opbg.net

'Department of Neuroscience, Child and Adolescent Neuropsychiatry Unit, Bambino Gesù Children's Hospital, IRCCS, Piazza Sant'Onofrio 4, 00165 Rome, Italy Full list of author information is available at the end of the article
}

wreaked havoc with Abruzzo infrastructures, historic and artistic patrimonies [1], causing over ten million euro in damages, according to the official estimates by the Italian Government. As of September 2012, more than 32,000 people are still displaced, benefiting from various governmental housing programmes [2].

Exposure to potentially traumatic events may be associated with a wide range of psychiatric disorders in children and adolescents. These conditions can have variable

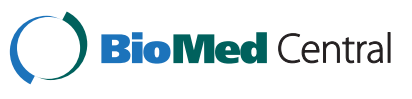

(C) 2014 Feo et al.; licensee BioMed Central Ltd. This is an Open Access article distributed under the terms of the Creative Commons Attribution License (http://creativecommons.org/licenses/by/2.0), which permits unrestricted use, distribution, and reproduction in any medium, provided the original work is properly credited. The Creative Commons Public Domain Dedication waiver (http://creativecommons.org/publicdomain/zero/1.0/) applies to the data made available in this article, unless otherwise stated. 
degrees of comorbidity, and a long-lasting impact on quality of life, and academic achievements [3-9].

Knowledge of the consequences of natural disasters on child and adolescent mental health is limited for several reasons. First, most studies conducted in the aftermath of disasters focused on post-traumatic stress (PTS) symptoms or PTS disorder (PTSD) and depressive symptoms or disturbances only. Secondly, most tools used to assess the mental health outcomes present unsatisfactory levels of sensitivity and specificity [6,10-12].

A meta-analysis of PTS in children after natural disasters [11] shows an association between the event and PTS $(\mathrm{d}=0.4)$, but the same meta-analysis and a systematic review of psychopathology in children survivors of disasters [12] also highlight a great variability in the disorders prevalence. In fact, in example, with regard to children exposed to earthquakes, studies show a PTSD prevalence of $2.5-95 \%[13,14]$ and a depression prevalence of $5.4-76 \%[14,15]$.

Focusing on data more relevant to the present study, between 12 and 18 months after natural disasters Wang et al. [12] report that data from preschool children community samples are lacking, while for school age children and early adolescents self-reported prevalence of PTS and depression symptoms ranges from, respectively, $11.2 \%$ and $11.3 \%$ at 12 months [16], to $12.4 \%$ and $13.9 \%$ at 15 months [17], to $95 \%$ and $76 \%$ at 18 months after an earthquake [14]. Prevalence tend to be lower when data are collected through a psychiatric interview: according to DSM-IV criteria [18], PTSD prevalence is found $2.1 \%-4.7 \% 18$ months after floods [19,20], while depression prevalence is found 5.4\% 18-20 months after an earthquake [15]. Nevertheless this trend is not absolute: when investigating very highly affected populations, even studies based on diagnostic assessment according to ICD-10 [21] found PTSD and depression prevalence of $30.6 \%$ and $23.7 \%$, respectively, 12 months after a super-cyclone [22], and others according to DSM-IV found 31.6\% PTSD and 5.5\% depression 12 months, and 10.4\% PTSD 18 months after the 2004 tsunami [23,24]. One of these two studies also examined preschool children; in the whole sample, thus including tsunami affected and non affected children, at this age prevalence of psychiatric disorders was found lower than in school age children $(2.3 \%$ vs $3.8-16.6 \%) 1$ year after the tsunami [23].

Methodological proposed explanations for the prevalence variability include differences of studied populations, time of assessment since the disaster and the use of self-report instruments $[6,10,11,25]$.

To reduce biases generated by single informants, a multi-informant assessment in post-disaster settings may be adopted. However, to our knowledge, this model was applied only to refugee children with parents reporting a higher prevalence of psychiatric symptoms than children; however, there was no clear cut explanation for this finding [26].

Severity of exposure to disasters, i.e. magnitude of the event, proximity to the epicentre, losses, perceived threat, are the most evident risk factors for children mental health. Female gender is often associated with PTS and PTSD. The role played by general mental health and reaction to trauma of parents and by the child's age on PTS symptoms is still a matter of debate [11]. Moreover, the frequent use of bivariate analysis in associating exposures with outcomes may miss the effect of potential confounders and other determinants of outcomes that would be best estimated by multivariate analysis $[27,28]$.

Despite the disasters that have occurred in Italy during the last decades, only a few studies focused on children and adolescents mental health. Six months after the 2002 earthquake in Molise, PTSD prevalence was $14.5 \%$ in an over 14 years community sample; however, data on adolescents were not disaggregated from those on adults [29].

Prevalence of PTSD in students attending the last year of high school in L'Aquila was $37.5 \%$ ten months after the earthquake and $30.7 \%$ twenty-one months after [30,31]. Additionally, $66.7 \%$ people aged seventeen to thirty years seeking help at the L'Aquila University Psychiatry Unit self-reported the presence of PTS symptoms in the first nine months after the earthquake; $13.8 \%$ were diagnosed with PTSD according to DSM-IV $[18,32]$. Children and adolescents affected by autism spectrum disorder who had experienced the L'Aquila earthquake showed a decline in adaptive behaviour at six months and at one year after the disaster [33]. Despite their public health relevance, no data are available on the prevalence of psychiatric symptoms in children and adolescents out of the general population after the L'Aquila earthquake.

Primary aims of the present study were to (i) measure the prevalence of a broad range of psychiatric symptoms in a community sample of children and pre-adolescents in Abruzzo after the 2009 earthquake, evaluating differences in outcomes between children resident in zones hit by the earthquake and those living in surrounding non-affected areas, and (ii) investigate the association of sociodemographic, health, family, and earthquakerelated factors with the psychiatric outcomes.

\section{Setting}

L'Aquila is the capital of Abruzzo in Central Italy. Abruzzo's population is over 1.3 million; the population under 18 years of age is over 210 thousand [34].

The National Health System provides full care coverage at no out-of-pocket cost through a network of 
general practitioners and family paediatricians (FPs). They maintain clinical records of all the residents and are connected with a capillary network of National Health System multidisciplinary community health units.

Ministry of Education ensures homogeneity of education system that is freely accessible and education is compulsory up to the age of 16 .

\section{Methods}

\section{Study design and sample}

This cohort study included the follow up of a group of children exposed to the earthquake. The first phase, which has a cross sectional design, aimed at assessing the prevalence of psychopathological symptoms in a community sample of children aged 3-14 years by using screening instruments. The second phase aimed at ascertaining the presence of psychiatric disorders according to DSM-IV in those cases screened in the first phase by a semi-structured clinical interview. This survey reports results of the first phase.

Psychopathological symptoms were screened 12 to 17 months after the disaster in a convenience sample. We contacted all Abruzzo FPs $(n=187)$. One hundred FPs agreed to participate and attended a preliminary training on clinical management of traumatic reactions in children, family counselling and research methodology. Fifty-four out of these FPs initially accepted to participate to the study, but after 17 dropped out, eventually, 37 FPs completed the research. The proportion of the 37 participating FPs did not significantly differ among provinces $\left(\mathrm{X}^{2}{ }_{3}=6.4, \mathrm{p}=0.093\right.$ ) (Figure 1 ).

All children and adolescents aged 3 to 14 years assigned to the participating FPs were eligible for participation,

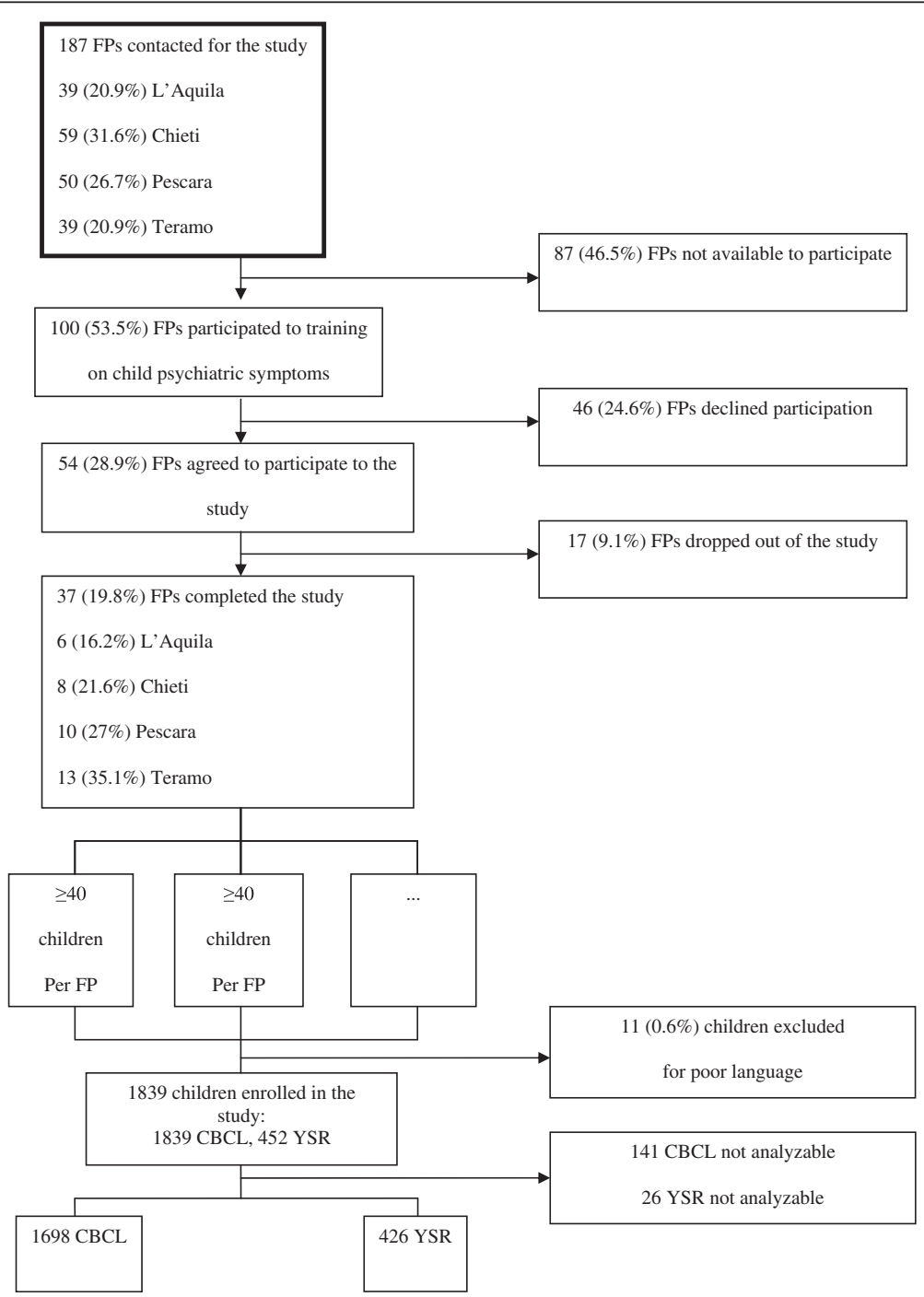

Figure 1 Flow diagram of the study selection process and study subsets. 
while families with insufficient knowledge of the Italian language were excluded.

To estimate the prevalence of psychiatric symptoms with a precision of $\pm 2 \%$, assuming an expected prevalence of $20 \%$, a power of $80 \%$ and a confidence level of $95 \%$, a sample size of 1448 subjects, over a reference population of 25,000 , was calculated.

Each participating FP enrolled at least 40 children in sequential order of presentation to consultation, in order to reach a total sample of at least 1448 children. Given the full coverage of the FPs network, each enrolling reservoir was assumed as corresponding to the total population of children and adolescents of that age resident in the same area of the assigned FP. The total enrolled sample consisted of 1850 children. Eleven children were excluded for their parents' insufficient knowledge of the Italian language (Figure 1).

A total of 1839 children aged 3-14 years (mean 8.3 years, SD 3.2) from all parts of Abruzzo participated in the screening. As mentioned above, their residence was assumed as corresponding to that of the assigned FP: 160 were resident in L'Aquila, the earthquake epicentre, 215 in the remainder earthquake zone, 1464 in the rest of the Region. Fifty-five children were conservatively considered as living in the unaffected area, though their assigned $3 \mathrm{FP}$ were resident in the same area at the border with the earthquake zone. All children were screened using the Child Behavior Checklist (CBCL) [35,36] and 452 children aged 11-14 were assessed by the Youth Self Report (YSR) [37]; 367 children aged 1114 were evaluated by both tools. One hundred forty-one CBCL and 26 YSR were excluded due to incomplete data, so that valid CBCL were completed for 1698 children $(92.3 \%$ of the targeted sample) and valid YSR for 426 children (94.3\%) (Figure 1). All children participating in the study were regularly attending the school. The vast majority of children were Caucasian and only 55 were from different ethnic groups.

The study was approved by both the Ethical Committee of Bambino Gesù Children's Hospital IRCCS and of the local National Health System health units. Informed written consent was obtained by the parents.

\section{Measures \\ Sociodemographic, medical health, family and earthquake- related factors}

An ad hoc questionnaire was developed and filled in by both parents, separately. Data concerning children were collected from their mothers. Sociodemographic, health and family data were: gender, age, parents' level of education, mother's marital status, current chronic physical disease, lifetime neuro-psychiatric condition, child's and parents mental health care sought or received after and before the earthquake, distinctly. Earthquake-related factors were: proximity to the epicentre (resident in the earthquake epicentre, remainder earthquake zone, unaffected areas), damages to the house, (past or present) internally displaced condition, parents' loss of job. When examining the association of these factors to CBCL outcomes, gender was analyzed as female versus male; age classes as, distinctly: age 6-10 years and 11-14 years versus 3-5 years; parents' education as at least a high school diploma versus not holding it; mother's marital status as married versus other conditions; child's proximity to disaster as, distinctly: resident in L'Aquila and in the remainder earthquake zone versus resident in unaffected areas; damages to the house as uninhabitable versus inhabitable.

\section{Psychiatric symptoms}

A multi-informant assessment approach was adopted using the CBCL and the YSR (self-report questionnaire of the CBCL package for children aged over 10 years). Above instruments investigate psychopathological symptoms in the Italian population [38], and were previously used in complex emergencies [26,39-43].

The children's psychiatric symptoms were measured by administering to parents the Child Behavior Checklist 1.5-5 or the Child Behavior Checklist 6-18 [36], according to the children's respective ages. Children aged 11-14 also filled the Youth Self Report (YSR) [25]. The Italian versions of CBCL and YSR were obtained through back-translation authorized and approved by T. Achenbach [38]. Cut-off points of clinical interest were identified according to the tool kit software standards: norms were based on $90^{\text {th }}$ percentile (Tscore $=63$ ) for Internalizing, Externalizing and Total Problems Scales, and on $97^{\text {th }}$ percentile (Tscore $=69$ ) for DSM-IV oriented and PTS scales [44]. Children were identified as subjects of public health interest, hereafter referred to as cases, when rated as clinical at Internalizing, or Externalizing, or Total Problems Scales. Main Symptoms patterns were identified in Anxiety and Affective DSM-related Scales and PTS Scale.

\section{Data analysis}

CBCL- and YSR-defined cases and symptoms prevalence was examined by being resident in L'Aquila, in the remainder earthquake zone, or in the unaffected areas. Chi-square was used to compare proportions. Step-wise forward multivariate logistic regression analysis was used to evaluate the effect of sociodemographic, health, family and earthquake-related factors on CBCL-defined cases and Main Symptoms that showed statistically significantly differences among residence groups in the whole sample. Odds ratios (ORs) were calculated to indicate the strength of association. Statistical significance was estimated using two-sided .05 tests. The independent 
variables included in the multivariate regression model had showed at least .20 statistical significance at univariate logistic regression analysis. 95\% confidence intervals (CI) were calculated for symptoms prevalence and odds ratio values.

\section{Results}

Sociodemographic, health, family and earthquake-related factors

The sociodemographic characteristics of the sample are summarized in Table 1. Most parents had at least a high school education, with mothers more frequently than fathers $(77.4 \%$ vs $66 \%)$. While no statistically significant difference was observed among fathers from different residence groups, this was observed among mothers (91.0\% in L'Aquila vs $67.0 \%$ in the remainder earthquake zone vs $74.8 \%$ in unaffected areas, $\chi_{2}^{2}=28.0, \mathrm{p}<.001$ ). Prevalence of children's chronic physical diseases and neuropsychiatric conditions was relatively low (respectively $3.3 \%$ and $2.4 \%$ ). Mental health care seeking for children was $5.1 \%$ before the earthquake, and $2.9 \%$ after the earthquake. In this case, L'Aquila children show a statistically significant higher prevalence than other residence groups $\left(9.5 \%\right.$ vs $3.3 \%$ vs $\left.2.0 \%, \chi_{2}^{2}=28.4, \mathrm{p}<.001\right)$.

More mothers than fathers had sought mental health care both before and after the earthquake, mothers in the epicentre had higher mental health services utilization than mothers in other areas both before the earthquake $\left(8.2 \%\right.$ vs $4.2 \%$ vs $\left.3.9 \%, \chi_{2}^{2}=6.2, p=.045\right)$ and afterwards $\left(6.3 \%\right.$ vs $1.9 \%$ vs $1.4 \%, \chi_{2}^{2}=18.3$, $\mathrm{p}<.001)$. Fathers in the epicentre showed increased mental health services utilization after the earthquake from $1.9 \%$ to $2.6 \%$.

A total of $22.2 \%$ of the children enrolled in the study were in the earthquake zone at the moment of the disaster. All earthquake-related factors show a statistically significant higher prevalence in L'Aquila $(\mathrm{p}<.001$ for all factors). Here uninhabitable houses were $74.1 \%$, internally displaced children $96.2 \%$, and parents' loss of job was $13.8 \%$ for mothers and $11.9 \%$ for fathers (Table 1 ).

\section{Psychiatric symptoms}

Prevalence of total CBCL-defined cases was 13.9\% (14.9\% in L'Aquila, $13.0 \%$ in the remainder earthquake zone, $13.9 \%$ in unaffected areas); their distribution

Table 1 Sociodemographic, medical health, family and earthquake-related factors of children by proximity to disaster

\begin{tabular}{|c|c|c|c|c|c|c|c|c|c|c|}
\hline & & \multicolumn{2}{|c|}{ Epicentre } & \multicolumn{2}{|c|}{$\begin{array}{l}\text { Remainder } \\
\text { earthquake zone }\end{array}$} & \multicolumn{2}{|c|}{$\begin{array}{l}\text { Unaffected } \\
\text { areas }\end{array}$} & \multicolumn{2}{|l|}{ Total } & \multirow[t]{2}{*}{$p$} \\
\hline & & $\mathrm{N}$ & $\%$ & $\mathrm{~N}$ & $\%$ & $\mathrm{~N}$ & $\%$ & $\mathrm{~N}$ & $\%$ & \\
\hline \multirow[t]{2}{*}{ Gender } & Females & 80 & 50.0 & 106 & 49.5 & 743 & 51.0 & 929 & 50.7 & - \\
\hline & Males & 80 & 50.0 & 108 & 50.5 & 714 & 49.0 & 902 & 49.3 & - \\
\hline \multirow[t]{3}{*}{ Age } & $3-5$ yrs & 48 & 30.0 & 63 & 29.3 & 467 & 31.9 & 578 & 31.5 & - \\
\hline & $6-10$ yrs & 73 & 45.6 & 98 & 45.6 & 608 & 41.6 & 779 & 42.4 & - \\
\hline & $11-14$ yrs & 39 & 24.4 & 54 & 25.1 & 388 & 26.5 & 481 & 26.2 & - \\
\hline \multirow[t]{2}{*}{ Parents' high school diploma } & Mother $(N=1703)$ & 141 & 91.0 & 132 & 67.0 & 1011 & 74.8 & 1284 & 75.4 & 0.000 \\
\hline & Father $(\mathrm{N}=1611)$ & 109 & 73.2 & 122 & 62.6 & 832 & 65.7 & 1063 & 66.0 & 0.106 \\
\hline Mother not married $(\mathrm{N}=1781)$ & & 7 & 4.4 & 18 & 8.5 & 127 & 9.0 & 152 & 8.5 & 0.148 \\
\hline Chronic physical diseases $(N=1766)$ & & 8 & 5.0 & 4 & 1.9 & 47 & 3.4 & 59 & 3.3 & 0.255 \\
\hline Lifetime Neuropsychiatric condition ( $N=1678$ ) & & 8 & 5.4 & 8 & 3.9 & 25 & 1.9 & 41 & 2.4 & 0.011 \\
\hline Pre-earthquake mental health care $(\mathrm{N}=1755)$ & & 10 & 6.3 & 13 & 6.1 & 67 & 4.8 & 90 & 5.1 & 0.563 \\
\hline Post-earthquake mental health care $(\mathrm{N}=1745)$ & & 15 & 9.5 & 7 & 3.3 & 28 & 2.0 & 50 & 2.9 & 0.000 \\
\hline \multirow[t]{2}{*}{ Parents' pre-earthquake mental health care } & Mother $(N=1749)$ & 13 & 8.2 & 9 & 4.2 & 54 & 3.9 & 76 & 4.4 & 0.045 \\
\hline & Father $(\mathrm{N}=1671)$ & 3 & 1.9 & 8 & 3.9 & 20 & 1.5 & 31 & 1.9 & 0.066 \\
\hline \multirow[t]{2}{*}{ Parents' post-earthquake mental health care } & Mother $(N=1735)$ & 10 & 6.3 & 4 & 1.9 & 19 & 1.4 & 33 & 1.9 & 0.000 \\
\hline & Father $(\mathrm{N}=1655)$ & 4 & 2.6 & 3 & 1.5 & 12 & 0.9 & 19 & 1.2 & 0.175 \\
\hline Present in the earthquake zone during the disaster $(N=1745)$ & & 152 & 98.7 & 172 & 82.7 & 63 & 4.6 & 387 & 22.2 & 0.000 \\
\hline Uninhabitable home after the earthquake $(N=1586)$ & & 117 & 74.1 & 23 & 10.9 & 176 & 14.5 & 316 & 19.9 & 0.000 \\
\hline Internally displaced $(\mathrm{N}=1464)$ & & 153 & 96.2 & 41 & 20.0 & 50 & 4.6 & 244 & 16.7 & 0.000 \\
\hline \multirow[t]{2}{*}{ Parents lost their job after the earthquake } & Mother $(N=1835)$ & 22 & 13.8 & 4 & 1.9 & 8 & 0.6 & 34 & 1.9 & 0.000 \\
\hline & Father $(\mathrm{N}=1835)$ & 19 & 11.9 & 0 & 0.0 & 10 & 0.7 & 29 & 1.6 & 0.000 \\
\hline
\end{tabular}


through age groups was significantly different $(10.8 \%$ at $3-5$ years, $15.9 \%$ at $6-10$ years, and $14.3 \%$ at $11-14$ years, $\mathrm{X}_{2}^{2}=6.9, \mathrm{p}=.032$ ); the highest prevalence of CBCL-defined cases was found in children aged 6-10 in L'Aquila (22.9\%). Prevalence of total YSR-defined cases was $4.5 \%$ (7.9\% in L'Aquila, no cases in the remainder earthquake zone, $4.7 \%$ in unaffected areas) (Table 2).

Internalizing symptoms were more frequent than externalizing symptoms either in the total sample $(11.7 \%$ vs $4.4 \%$ ) and in each residence group. Main Symptoms were always more frequent in L'Aquila, but only PTS showed statistically significant differences among residence groups $\left(8.4 \%\right.$ vs $4.0 \%$ vs $\left.2.2 \%, \chi_{2}^{2}=13.0, p=.002\right)$ (Table 2$)$.

Analysis of the prevalence of CBCL and YSR symptoms in the three residence groups was conducted separately for the three age ranges. The only statistically significant differences were found in the 6-10 years group, concerning Main Symptoms: anxiety $(15.7 \%$ vs $6.2 \%$ vs $\left.6.3 \%, \mathrm{x}_{2}^{2}=8.5, \mathrm{p}=.014\right)$ and PTS $(10.0 \%$ vs $4.1 \%$ vs $\left.2.8 \%, X_{2}^{2}=9.3, p=.009\right)$. Affective problems showed the same prevalence pattern but did not achieve statistical significance $\left(10.0 \%\right.$ vs $5.2 \%$ vs $3.8 \%, \chi_{2}^{2}=5.5$, $\mathrm{p}=.064)$ (Table 3).
Association of sociodemographic, health, family and earthquake-related factors with CBCL-defined cases and main symptoms that showed significantly different distributions

CBCL-defined cases were equally strongly predicted by child's pre-earthquake and mother's post-earthquake mental health care seeking (respectively: OR $=5.7,95 \%$ $\mathrm{CI}=3.5-9.4, \mathrm{p}<.001 ; \mathrm{OR}=5.6,95 \% \mathrm{CI}=2.7-11.7, \mathrm{p}<.001)$. Child's chronic diseases were also associated to CBCLdefined cases $(\mathrm{OR}=2.0,95 \% \mathrm{CI}=1.0-4.0, \mathrm{p}=.047)$ even if with lower intensity and statistical significance, while father's education showed to be a protective factor $(\mathrm{OR}=0.7$, 95\% CI $=0.5-1.0, \mathrm{p}=.041$ ).

Both PTS and anxiety symptoms, the first more than the second, were predicted by child's and mother's preearthquake mental health care seeking (child: $\mathrm{OR}=7.1$, $95 \% \mathrm{CI}=3.1-16.2, \mathrm{p}<.001$ for $\mathrm{PTS}$; OR $=4.0,95 \% \mathrm{CI}=$ 2.2-7.2, $\mathrm{p}<.001$ for anxiety; mother: $\mathrm{OR}=4.5,95 \%$ $\mathrm{CI}=1.7-11.8, \mathrm{p}=.002$ for PTS; OR $=3.2,95 \% \mathrm{CI}=1.7$ $6.1, \mathrm{p}<.001$ for anxiety). PTS was the only condition predicted by earthquake direct related factors as living in L'Aquila, the epicentre $(\mathrm{OR}=3.6,95 \% \mathrm{CI}=1.5-8.6$, $\mathrm{p}=.004)$.

Table 2 CBCL and YSR-defined Cases by age groups and proximity to disaster and symptoms at CBCL by proximity to disaster

\begin{tabular}{lllll} 
Epicentre & Remainder earthquake zone & Unaffected areas & Total & p \\
\cline { 3 - 4 } & $(\%)$ & $(\%)$ & $\mathrm{N}$ & $\%$
\end{tabular}

\section{CBCL-defined cases}

\begin{tabular}{|c|c|c|c|c|c|c|}
\hline Total sample & 14.9 & 13.0 & 13.9 & 1698 & 13.9 & 0.876 \\
\hline Children 3-5ys & 8.5 & 10.3 & 11.1 & 545 & 10.8 & 0.853 \\
\hline Children 6-10ys & 22.9 & 13.4 & 15.5 & 741 & 15.9 & 0.218 \\
\hline Children 11-14ys & 8.1 & 15.4 & 14.9 & 412 & 14.3 & 0.525 \\
\hline \multicolumn{7}{|l|}{ YSR-defined cases } \\
\hline Children 11-14ys & 7.9 & 0.0 & 4.7 & 426 & 4.5 & 0.198 \\
\hline \multicolumn{7}{|l|}{ CBCL symptoms } \\
\hline Total & 9.2 & 6.5 & 6.9 & 1698 & 7.1 & 0.465 \\
\hline Internalizing & 10.6 & 13.6 & 11.7 & 1698 & 11.7 & 0.674 \\
\hline Externalizing & 5.3 & 5.8 & 4.0 & 1698 & 4.4 & 0.450 \\
\hline Affective & 5.2 & 2.9 & 3.3 & 1698 & 3.4 & 0.426 \\
\hline Anxiety & 11.0 & 5.3 & 6.7 & 1698 & 6.9 & 0.085 \\
\hline PTS $^{\mathrm{a}}$ & 8.4 & 4.0 & 2.2 & 1153 & 3.0 & 0.002 \\
\hline Somatic $^{a}$ & 5.6 & 0.7 & 2.8 & 1151 & 2.8 & 0.060 \\
\hline $\mathrm{ADH}$ & 2.4 & 3.3 & 2.2 & 1698 & 2.4 & 0.738 \\
\hline Oppositional defiant & 1.0 & 1.3 & 0.5 & 1698 & 0.6 & 0.436 \\
\hline Conduct $^{a}$ & 0.7 & 0.9 & 0.8 & 1153 & 0.8 & .972 \\
\hline Pervasive development ${ }^{a}$ & 1.7 & 0.0 & 1.6 & 545 & 1.5 & 0.680 \\
\hline
\end{tabular}

Note: Valid numbers $(\mathrm{N})$ are expressed as quantities, all other data are expressed in percentages (\%).

Differences among the subsamples from different areas are calculated by $X^{2}$ test.

$\mathrm{ADH}$, attention deficit and hyperactivity; $\mathrm{CBCL}$, Child Behavior Checklist; PTS, post-traumatic stress; YSR, Youth Self Report

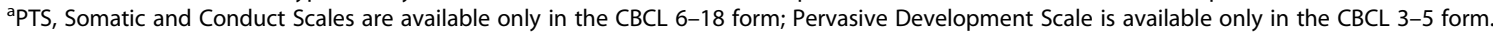


Table 3 Prevalence of CBCL- and YSR-defined cases and symptoms at the CBCL and YSR scales by age group and proximity to disaster

\begin{tabular}{|c|c|c|c|c|c|c|c|c|c|c|}
\hline & \multicolumn{5}{|l|}{ CBCL 3-5 ys } & \multicolumn{5}{|l|}{ CBCL 6-10 ys } \\
\hline & Earthquake epicentre & Remainder earthquake zone & Unaffected areas & Total & $\mathbf{p}$ & Earthquake epicentre & Remainder earthquake zone & Unaffected areas & Total & $\mathrm{p}$ \\
\hline Valid Number & 47 & 58 & 440 & 545 & & 70 & 97 & 574 & 741 & \\
\hline Cases & 8.5 & 10.3 & 11.1 & 10.8 & 0.853 & 22.9 & 13.4 & 15.5 & 15.9 & 0.218 \\
\hline \multicolumn{11}{|l|}{ Problems } \\
\hline Total & 2.1 & 10.3 & 6.1 & 6.2 & 0.219 & 10.0 & 8.3 & 7.1 & 7.6 & 0.669 \\
\hline Internalizing & 6.4 & 6.9 & 9.8 & 9.2 & 0.610 & 21.4 & 11.3 & 12.9 & 13.5 & 0.114 \\
\hline Externalizing & 2.1 & 5.2 & 2.7 & 2.9 & 0.551 & 8.6 & 6.2 & 5.1 & 5.5 & 0.456 \\
\hline Affective & 0.0 & 0.0 & 3.2 & 2.6 & 0.180 & 10.0 & 5.2 & 3.8 & 4.6 & 0.064 \\
\hline Anxiety & 6.4 & 1.7 & 7.3 & 6.6 & 0.278 & 15.7 & 6.2 & 6.3 & 7.2 & 0.014 \\
\hline PTS & - & - & - & - & - & 10.0 & 4.1 & 2.8 & 3.6 & 0.009 \\
\hline Somatic & - & - & - & - & - & 2.9 & 0.0 & 1.9 & 1.8 & 0.314 \\
\hline ADH & 4.3 & 3.5 & 2.1 & 2.4 & 0.547 & 4.3 & 1.0 & 2.6 & 2.6 & 0.417 \\
\hline Oppositional defiant & 0.0 & 1.7 & 0.5 & 0.6 & 0.408 & 2.9 & 1.0 & 0.9 & 1.1 & 0.316 \\
\hline Conduct & - & - & - & - & - & 0.0 & 1.0 & 0.5 & 0.5 & 0.664 \\
\hline Pervasive development & 0.0 & 1.7 & 1.6 & 1.5 & 0.680 & - & - & - & - & - \\
\hline
\end{tabular}


Table 3 Prevalence of CBCL- and YSR-defined cases and symptoms at the CBCL and YSR scales by age group and proximity to disaster (Continued)

\begin{tabular}{|c|c|c|c|c|c|c|c|c|c|c|}
\hline & \multicolumn{5}{|l|}{ CBCL 11-14 ys } & \multicolumn{5}{|l|}{ YSR $11-14$ ys } \\
\hline & Earthquake epicentre & Remainder earthquake zone & Unaffected Areas & Total & $\mathbf{p}$ & Earthquake epicentre & Remainder earthquake zone & Unaffected areas & Total & $\mathrm{p}$ \\
\hline Valid Number & 37 & 52 & 323 & 412 & & 38 & 46 & 342 & 426 & \\
\hline Cases & 8.1 & 15.4 & 14.9 & 14.3 & 0.525 & 7.9 & 0.0 & 4.7 & 4.5 & 0.198 \\
\hline \multicolumn{11}{|l|}{ Problems } \\
\hline Total & 5.4 & 9.6 & 7.4 & 7.5 & 0.752 & 7.9 & 0.0 & 2.9 & 3.1 & 0.106 \\
\hline Internalizing & 8.1 & 13.5 & 12.1 & 11.9 & 0.727 & 7.9 & 0.0 & 3.2 & 3.3 & 0.128 \\
\hline Externalizing & 5.4 & 3.9 & 4.0 & 4.1 & 0.918 & 0.0 & 0.0 & 1.8 & 1.4 & 0.474 \\
\hline Affective & 2.7 & 1.9 & 2.5 & 2.4 & 0.965 & 0.0 & 0.0 & 0.9 & 0.7 & 0.690 \\
\hline Anxiety & 8.1 & 7.7 & 6.8 & 7.0 & 0.940 & 2.6 & 0.0 & 1.2 & 1.2 & 0.537 \\
\hline PTS & 5.4 & 3.9 & 1.2 & 1.9 & 0.125 & 2.6 & 0.0 & 0.9 & 0.9 & 0.445 \\
\hline Somatic & 10.8 & 1.9 & 4.3 & 4.6 & 0.126 & 2.6 & 0.0 & 2.3 & 2.1 & 0.569 \\
\hline ADH & 0.0 & 3.9 & 1.9 & 1.9 & 0.420 & 2.6 & 2.2 & 1.5 & 1.6 & 0.827 \\
\hline Oppositional defiant & 0.0 & 0.0 & 0.0 & 0.0 & - & 2.6 & 0.0 & 1.5 & 1.4 & 0.585 \\
\hline Conduct & 2.7 & 0.0 & 1.2 & 1.2 & 0.516 & 0.0 & 0.0 & 0.9 & 0.7 & 0.690 \\
\hline Pervasive development & - & - & - & - & - & - & - & - & - & - \\
\hline
\end{tabular}

Note: Valid numbers are expressed as quantities, all other data are expressed in percentages.

Differences among the subsamples from different areas are calculated by $X^{2}$ test.

ADH, attention deficit and hyperactivity; CBCL, Child Behavior Checklist; PTS, post-traumatic stress; YSR, Youth Self Report. 


\section{Discussion}

To the best of our knowledge, this is the first study investigating the prevalence of psychiatric symptoms in an Italian community sample of children and adolescents after a natural disaster.

Children who needed psychiatric care 12 to 17 months after the earthquake were about $14 \%$ of the examined population. This proportion is consistent with that reported by parents (about 15\%) in a representative sample of children and adolescents 2 years after the Hurricane Katrina [45].

The prevalence of internalizing symptoms (about 12\%) was found equal to that found through diagnostic interview in a large random community sample of children and adolescents 18 months after the Hurricane Georges [46]. Within internalizing spectrum the expression of anxiety symptoms was higher than that of PTS and affective symptoms across age and proximity to disaster; an analogous pattern was observed in school age children and early adolescents after the Sichuan earthquake $[16,47]$, and in adolescents after the Hurricane Georges [48].

PTS symptoms increased in the whole epicentre community likewise found elsewhere 15 months after an earthquake $[16,17]$, but the rise was more pronounced in the children aged 6-10. In this group, prevalence of risk of psychiatric disorders (22.9\%) reached levels predicted by the World Health Organization during the first year after disaster (23-24\%) [49]. This finding would support that such estimated prevalence may remain stable or only gradually decrease over the first year in children and adolescents, or at least in specific groups, as documented by other studies [15,22-24,45,50-52].

The comparison with previous investigations in Italian population, although limited by the substantial lack of data, allows to evidence one closely methodological interesting point. We reported a higher prevalence of CBCL-defined cases in 11-14 years children than Frigerio et al. [53] in a 10-14 years urban community sample in ordinary setting (14.3\% vs $9.8 \%)$. Our CBCL and YSR findings are consistent with PTSD results in young adults who received a clinical diagnosis according to DSM-IV nine months after the earthquake [32], while they are inconsistent with self-reported PTS symptoms in late adolescents and young adults in the same period $[30,32]$. Therefore, taking together these observations, we could argue that the investigation in a large community sample and the use of a culturally appropriate screening tool with satisfying psychometric properties as those we used, can help to obtain a more reliable estimation of psychiatric morbidity.

Age significantly affected the expression of psychiatric symptoms. Consistently with another other study based on diagnostic interview [24], pre-school children showed lower prevalence than elder children. Indeed, 6-10 years children had significantly higher burden associated with exposure to the earthquake, and their psychopathological pattern was consistent with most findings reported in literature $[7,11,12,49]$. In fact, a higher prevalence of CBCL-defined cases, anxiety and PTS symptoms was found in the epicentre at this age; also depressive symptoms were almost significantly higher in the epicentre. However, no association was found in our study between this age range and psychiatric outcomes. While on the one hand it may be inferred that the higher susceptibity may have been mediated by still immature coping strategies no longer mediated by the care-giver shell [3], on the other hand it is possible that non investigated factors, as in example a lack of social support, may have played relevant role for these children. Nevertheless, as children in this age group were not univocally considered vulnerable by studies in ordinary settings $[53,54]$ and in complex emergencies $[11,12,20,22,45-47]$, further investigation is needed to fully explain the observed developmental trend.

The expected small gender effect on psychiatric symptoms $[11,55]$ was disconfirmed by our findings as also occurred in other studies $[20,22,56]$. As gender differences in internalizing symptoms typically emerge since puberty when these are more relevant in girls [57], it is possible that the relatively low prevalence of this symptoms spectrum in the whole sample and in the 11-14 years group may have reduced the effect of gender to non significant levels.

Our study extends the investigation from the wellestablished impact of exposure to disaster to health and family factors that may contribute to understand the role of ecological resources with regards to post-disaster outcomes [58].

Parents' education had a protective role on children mental health, consistently with international literature $[20,59]$ and extending previous association found in Italian pre-adolescents to earlier ages [53].

While the degree of exposure to the earthquake only affected PTS symptoms, psychiatric symptoms in children were strongly associated with different individual and family health conditions. Children's chronic physical diseases doubled the risk of current psychiatric symptoms. Despite no other study examined this association in aftermath of disasters up to our knowledge, this finding supports the link between general and mental health often invoked in global mental health promotion [60]. It is to be wished that future research will take this major factor into account, because of the relevant implications for mental health services organization and integration with other health services in complex emergencies.

Moreover, the presence of premorbid conditions of mental sufferance in child or in his/ her mother showed the strongest and widest predictive value, raising this 
risk up to five - seven times. The impact of child pre-disaster and mother's pre- and post-disaster mental health is consistent with results of several previous studies $[19,20,30,56,59,61-67]$. In our case, it may bolster two hypotheses: a direct trans-generational effect on child's psychiatric outcomes, or a confounding effect on child's symptoms she reports. This last instance may partly explain the disagreement between parent- and childreported symptoms in the sense of an overestimation of CBCL symptoms prevalence. However, these findings underline the need of investigating prior conditions in research, and set a clear public health priority in planning post-disaster mental health and psychosocial interventions.

Strengths of the study are the large size and age range of the community sample, and the distribution of the enrolment sources consistent with the geographical distribution of all Regional FPs warranting to some extent the sample representativeness despite the convenience sampling procedure. Moreover, a wide range of disorders were examined by a psychometrically robust screening tool, and some pre-disaster factors were taken into account beyond trauma exposure.

The study also presents some limitations. Despite the above mentioned attempt to reduce biases our is a convenience sample, and the enrolling strategy may have contributed to a potential over-estimation of results. In fact, being the children enrolled in sequential order of presentation to consultation, it is possible that our sample consists of a higher proportion of children affected by physical illness or psychopathology, or cared by a disordered parent, than the general population. In addition, the self-report assessment may reduce reliability of some scales, where under- or over-estimations are generated by mothers or children themselves. Some predictive factors like other pre-disaster life events, pre- and postdisaster functioning, perceived threat and social support were not studied. Moreover, no baseline prevalence is available in Abruzzo children, thus limiting the possible inferences on the results.

\section{Conclusion}

Twelve to 17 months after the L'Aquila earthquake, the number of children at risk of psychiatric disorders resulted relatively low and similar to the prevalence found in most western non emergency setting studies. Nevertheless, children aged 6-10 years living in the earthquake epicentre present a high risk of psychiatric disturbances, consistent with studies conducted in complex emergencies.

Our study confirms the need to empower the primary care system to improve the screening, monitoring, management and referral aimed at assessing and meeting the children's mental health needs as part of the post- disaster interventions $[68,69]$. The study also highlights the importance of taking into account PTS, anxiety and depressive symptoms in complex emergencies, the importance of analysing predictive factors other than earthquake-related, and the relevance of adopting a multi-informant approach for both clinical implications and advance in research. Further epidemiological studies in non emergency settings would be very supportive for indicating a baseline that would warrant a deeper understanding of the effect of major events, such as disasters.

\section{Abbreviations}

CBCL: Child Behavior Checklist; FPs: Family paediatricians; PTS: Post-traumatic stress; PTSD: Post-traumatic stress disorder; YSR: Youth Self Report

\section{Competing interests}

The authors declare that they have no competing interests.

\section{Authors' contributions}

PF executed the statistical analysis of part of the data and drafted the first version of the manuscript. SDG participated in the drafting of the first version of the manuscript. EC executed the statistical analysis of part of the data and participated in the drafting of the manuscript. BV participated in the drafting of the manuscript. AET participated in the design of study, supervised the statistical analysis and participated in the drafting of the manuscript. SV participated in the design of study and participated in the drafting of the manuscript. All authors read and approved the final manuscript.

\section{Acknowledgements}

The study was supported by the Ministers of the Infirm - Camillians - and Caritas Italiana, which are gratefully acknowledged, and was conducted thanks to the collaboration of the Italian Federation of Paediatricians (FIMP) and Abruzzo Family Paediatricians of the National Health System: C Albano, PMC Battistella, MT Bontempo, G Caravelli, MF Chiarieri, G Ciarelli, V Curti, N D'Amario, G De Felice, P De Gregorio, E Del Vomano, F Di Croce, T Di Giampietro, A Di Marzio, P Di Saverio, M Ferretti, T Galante, G Giampaolo, V Ippoliti, A Lamborghini, M Lanci, G Lanciaprima, M Lepido, MG Libertini, MR Lombari, A Magnelli, L Marchione, DM Molina Meli, M Napoleone, R Nardi, G Olivieri, M Passali, R Rosati, RA Sacco, A Santilli, MR Sisto, ML Zaino. We thank the children and parents who participated, for their precious help.

\section{Author details}

'Department of Neuroscience, Child and Adolescent Neuropsychiatry Unit, Bambino Gesù Children's Hospital, IRCCS, Piazza Sant'Onofrio 4, 00165 Rome, Italy. ${ }^{2}$ Multifactorial Diseases and Complex Phenotypes Research Area, Bambino Gesù Children's Hospital, IRCCS, Rome, Italy. ${ }^{3}$ National Institute of Mental Health, Bethesda, Maryland, USA.

Received: 25 October 2013 Accepted: 16 September 2014 Published online: 24 September 2014

\section{References}

1. Dipartimento della Protezione Civile, Presidenza del Consiglio dei Ministri: Un anno in dieci punti: 6 aprile 2009-6 aprile 2010. In [http://www. protezionecivile.gov.it/jcms/en/emergenza_abruzzo_unanno.wp? request_locale=en]

2. II Commissario delegato per la Ricostruzione. Ufficio Coordinamento Ricostruzione: Report sulla situazione della popolazione post-sisma al 29 maggio 2012. In [http://www.commissarioperlaricostruzione.it/Informare/ Situazione-della-popolazione-post-Sisma/Report-sulla-situazione-dellapopolazione-post-sisma-al-29-maggio-2012]

3. Pynoos RS, Steinberg AM, Wraith R: A developmental model of childhood traumatic stress. In Developmental psychopathology, Volume 2. Edited by Cohen DJ, Cicchetti D. Oxford, United Kingdom: Wiley; 1995:72-95.

4. Norris FH, Friedman MJ, Watson PJ, Byrne CM, Diaz E, Kaniasty K: 60,000 disaster victims speak: Part I. An empirical review of the empirical literature, 1981-2001. Psychiatry 2002, 65(3):207-239. 
5. Caffo E, Belaise C: Psychological aspects of traumatic injury in children and adolescents. Child Adolesc Psychiatr Clin N Am 2003, 12(3):493-535.

6. Attanayake V, McKay R, Joffres M, Singh S, Burkle F Jr, Mills E: Prevalence of mental disorders among children exposed to war: A systematic review of 7,920 children. Med Confl Surviv 2009, 25(1):4-19.

7. Kar N: Psychological impact of disasters on children: Review of assessment and interventions. World J Pediatr 2009, 5(1):5-11.

8. Trickey D, Siddaway AP, Meiser-Stedman R, Serpell L, Field AP: A metaanalysis of risk factors for post-traumatic stress disorder in children and adolescents. Clin Psychol Rev 2012, 32(2):122-138.

9. Weems CF, Scott BG, Taylor LK, Cannon MF, Romano DM, Perry AM: A theoretical model of continuity in anxiety and links to academic achievement in disaster-exposed school children. Dev Psychopatho 2013, 25(3):729-737.

10. Pfefferbaum B, North CS: Research with children exposed to disasters. Int J Methods Psychiatr Res 2008, 17(Suppl 2):S49-S56.

11. Furr JM, Comer JS, Edmunds JM, Kendall PC: Disasters and youth: A meta-analytic examination of posttraumatic stress. J Consult Clin Psychol 2010, 78(6):765-780.

12. Wang CW, Chan $\mathrm{CL}$, Ho RT: Prevalence and trajectory of psychopathology among child and adolescent survivors of disasters: a systematic review of epidemiological studies across 1987-2011. Soc Psychiatry Psychiatr Epidemiol 2013, 48(11):1697-1720.

13. Ma X, Liu X, Hu X, Qiu C, Wang Y, Huang Y, Wang Q, Zhang W, Li T: Risk indicators for post-traumatic stress disorder in adolescents exposed to the 5.12 Wenchuan earthquake in China. Psychiatry Res 2011, 189(3):385-391.

14. Goenjian AK, Pynoos RS, Steinberg AM, Najarian LM, Asarnow JR, Karayan I, Ghurabi M, Fairbanks LA: Psychiatric comorbidity in children after the 1988 earthquake in Armenia. J Am Acad Child Adolesc Psychiatry 1995, 34(9):1174-1184.

15. Eksi A, Braun KL: Over-time changes in PTSD and depression among children surviving the 1999 Istanbul earthquake. Eur Child Adolesc Psychiatry 2009, 18(6):384-391.

16. Dong $X Y$, Zhao PL, Shi ZB: Post-trauma mental health problem among 8-14 year old children and its risk factors one year after Sichuan earthquake in Mianyang. Chin J Clin Psychol 2010, 18(6):753-755.

17. Jia Z, Tian W, He X, Liu W, Jin C, Ding H: Mental health and quality of life survey among child survivors of the 2008 Sichuan earthquake. Qual Life Res 2010, 19(9):1381-1391

18. American Psychiatric Association: Diagnostic and statistical manual of mental health disorders. 4th edition. Washington DC: American Psychiatric Association; 1994

19. Peng M, Liu A, Zhou J, Wen S, Li S, Yang T, Li X, Huang X, Abuaku B, Tan H: Association between posttraumatic stress disorder and preflood behavioral characteristics among children aged 7-15 years in Hunan, China. Med Princ Pract 2011, 20(4):336-340.

20. Li $X$, Huang $X$, Tan H, Liu A, Zhou J, Yang T: A study on the relationship between posttraumatic stress disorder in flood victim parents and children in Hunan, China. Aust N Z J Psychiatry 2010, 44(6):543-550.

21. World Health Organization: The ICD - 10 Classification of Mental Behavioural Disorders - Diagnostic Criteria for Research. Geneva: World Health Organization; 1992

22. Kar N, Mohapatra PK, Nayak KC, Pattanaik P, Swain SP, Kar HC: Post-traumatic stress disorder in children and adolescents one year after a super-cyclone in Orissa, India: exploring cross-cultural validity and vulnerability factors. BMC Psychiatry 2007, 7:8.

23. Piyasil V, Ketumarn $P$, Prubrukarn $R$, Pacharakaew S, Dumrongphol $H_{\text {, }}$ Rungsri S, Sitdhiraksa N, Pitthayaratsathien N, Prasertvit J, Sudto K, Theerawongseree S, Aowjinda S, Thaeramanophab S, Jotipanu V, Chatchavalitsakul W: Psychiatric disorders in children at one year after the tsunami disaster in Thailand. J Med Assoc Thai 2008, 91(Suppl 3):S15-S20.

24. Piyasil V, Ketuman P, Plubrukarn R, Jotipanut V, Tanprasert S, Aowjinda S, Thaeeromanophap S: Post traumatic stress disorder in children after tsunami disaster in Thailand: 2 years follow-up. J Med Assoc Thai 2007, 90(11):2370-2376

25. Rodin D, van Ommeren M: Commentary: Explaining enormous variations in rates of disorder in trauma-focused psychiatric epidemiology after major emergencies. Int J Epidemiol 2009, 38(4):1045-1048.

26. Mollica RF, Poole C, Son L, Murray CC, Tor S: Effects of war trauma on Cambodian refugee adolescents' functional health and mental health status. J Am Acad Child Adolesc Psychiatry 1997, 36(8):1098-1106.
27. Kessler RC, Davis CG, Kendler KS: Childhood adversity and adult psychiatric disorder in the US national comorbidity survey. Psychol Med 1997, 27(5):1101-1119.

28. Salcioglu E, Basoglu M: Psychological effects of earthquakes in children: Prospects for brief behavioral treatment. World J Pediatr 2008, 4(3):165-172.

29. Priebe S, Grappasonni I, Mari M, Dewey M, Petrelli F, Costa A: Posttraumatic stress disorder six months after an earthquake: Findings from a community sample in a rural region in Italy. Soc Psychiatry Psychiatr Epidemiol 2009, 44(5):393-397.

30. Dell'Osso L, Carmassi C, Massimetti G, Daneluzzo E, Di Tommaso S, Rossi A Full and partial PTSD among young adult survivors 10 months after the L'Aquila 2009 earthquake: Gender differences. J Affect Disord 2011, 131(1-3):79-83.

31. Dell'Osso L, Carmassi C, Massimetti G, Conversano C, Daneluzzo E, Riccardi I, Stratta P, Rossi A: Impact of traumatic loss on post-traumatic spectrum symptoms in high school students after the L'Aquila 2009 earthquake in Italy. J Affect Disord 2011, 134(1-3):59-64.

32. Pollice R, Bianchini V, Roncone R, Casacchia M: Psychological distress and post-traumatic stress disorder (PTSD) in young survivors of L'aquila earthquake. Riv Psichiatr 2012, 47(1):59-64.

33. Valenti M, Ciprietti T, Egidio CD, Gabrielli M, Masedu F, Tomassini AR, Sorge $\mathrm{G}$ : Adaptive response of children and adolescents with autism to the 2009 earthquake in L'aquila, Italy. J Autism Dev Disord 2012, 2(6):954-960.

34. Istituto Nazionale di Statistica: Demografia in cifre. In [http://demo.istat.it/ pop2010/index.html]

35. Achenbach TM, Rescorla LA: Manual for the ASEBA Preschool Forms \& Profiles. Burlington, VT: University of Vermont, Research Center for Children, Youth, and Families; 2000

36. Achenbach TM, Rescorla LA: Manual for the ASEBA School-Age Forms \& Profiles. Burlington, VT: University of Vermont, Research Center for Children, Youth, and Families; 2001.

37. Achenbach TM: Manual for the youth self-report and 1991 profile. Burlington, VT: University of Vermont, Department of Psychiatry; 1991

38. Frigerio A, Cattaneo C, Cataldo MG, Schiatti A, Molteni M, Battaglia M: Behavioral and emotional problems among Italian children aged 4-18 years as reported by parents and teachers. Eur J Psychol Assess 2004, 20(2):124-133.

39. Sourander $\mathrm{A}$ : Behavior problems and traumatic events of unaccompanied refugee minors. Child Abuse Negl 1998, 22(7):719-727.

40. Sundelin-Wahlsten $V$, Ahmad A, von Knorring AL: Traumatic experiences and post-traumatic stress reactions in children from kurdistan and sweden. Acta Paediatr 2001, 90(5):563-568.

41. Vila G, Witkowski P, Tondini MC, Perez-Diaz F, Mouren-Simeoni MC, Jouvent R: A study of posttraumatic disorders in children who experienced an industrial disaster in the Briey region. Eur Child Adolesc Psychiatry 2001, 10(1):10-18.

42. Vijayakumar L, Kannan GK, Daniel SJ: Mental health status in children exposed to tsunami. Int Rev Psychiatry 2006, 18(6):507-513.

43. Chartrand MM, Frank DA, White LF, Shope TR: Effect of parents' wartime deployment on the behavior of young children in military families. Arch Pediatr Adolesc Med 2008, 162(11):1009-1014.

44. Achenbach System of Empirically Based Assessment: Assessment Data Manager (ADM). Burlington, VT: University of Vermont; 1999.

45. McLaughlin KA, Fairbank JA, Gruber MJ, Jones RT, Lakoma MD, Pfefferbaum B, Sampson NA, Kessler RC: Serious emotional disturbance among youths exposed to hurricane Katrina 2 years postdisaster. J Am Acad Child AdolesC Psychiatry 2009, 48(11):1069-1078.

46. Felix E, You S, Vernberg E, Canino G: Family influences on the long term post-disaster recovery of Puerto Rican youth. J Abnorm Child Psychol 2013, 41(1):111-124

47. Liu M, Wang L, Shi Z, Zhang Z, Zhang K, Shen Z: Mental health problems among children one-year after Sichuan earthquake in China: a follow-up study. PloS One 2011, 6(2):e14706.

48. Rubens SL, Vernberg EM, Felix ED, Canino G: Peer deviance, social support, and symptoms of internalizing disorders among youth exposed to Hurricane Georges. Psychiatry 2013, 76(2):169-181.

49. van Ommeren M, Saxena S, Saraceno B: Aid after disasters. BMJ 2005, 330(7501):1160-1161

50. Jia Z, Shi L, Duan G, Liu W, Pan X, Chen Y, Tian W: Traumatic experiences and mental health consequences among child survivors of the 2008 
Sichuan earthquake: a community-based follow-up study. BMC Public Health 2013, 13:104.

51. Kar N, Bastia BK: Post-traumatic stress disorder, depression and generalised anxiety disorder in adolescents after a natural disaster: a study of comorbidity. Clin Pract Epidemiol Ment Health 2006, 2:17.

52. Weems CF, Taylor LK, Cannon MF, Marino RC, Romano DM, Scott BG, Perry AM, Triplett V: Post traumatic stress, context, and the lingering effects of the hurricane Katrina disaster among ethnic minority youth. J Abnorm Child Psychol 2010, 38(1):49-56.

53. Frigerio A, Rucci P, Goodman R, Ammaniti M, Carlet O, Cavolina P, De Girolamo G, Lenti C, Lucarelli L, Mani E, Martinuzzi A, Micali N, Milone A, Morosini P, Muratori F, Nardocci F, Pastore V, Polidori G, Tullini A, Vanzin L, Villa L, Walder M, Zuddas A, Molteni M: Prevalence and correlates of mental disorders among adolescents in Italy: The PrISMA study. Eur Child Adolesc Psychiatry 2009, 18(4):217-226.

54. Rutter M, Bishop D, Pine D, Scott S, Stevenson J, Taylor E, Thapar A: Rutter's Child and Adolescent Psychiatry. 5th edition. Oxford, United Kingdom: Blackwell; 2008.

55. Tolin DF, Foa EB: Sex differences in trauma and posttraumatic stress disorder: A quantitative review of 25 years of research. Psychol Bull 2006 132(6):959-992.

56. Felix E, Hernández LA, Bravo M, Ramirez R, Cabiya J, Canino G: Natural disaster and risk of psychiatric disorders in Puerto Rican children. J Abnorm Child Psychol 2011, 39(4):589-600.

57. Angold A, Worthman C, Costello EJ: Puberty and depression. In Gender differences at puberty. Edited by Hayward C. New York, NY: Cambridge University Press; 2003:137-164.

58. Tol WA, Jordans MJD, Reis R, de Jong JTVM: Ecological resilience: working with child-related psychosocial resources in war-affected communities. In Treating Traumatized Children: Risk, Resilience, and Recovery. Edited by Brom D, Pat-Horenczyk R, Ford J. London: Routledge; 2009.

59. Gil-Rivas V, Kilmer RP: Children's adjustment following Hurricane Katrina: the role of primary caregivers. Am J Orthopsychiatry 2013, 83(2Pt3):413-421.

60. Prince M, Patel V, Saxena S, Maj M, Maselko J, Phillips MR, Rahman A: No health without mental health. Lancet 2007, 370(9590):859-877.

61. La Greca AM, Silverman WK, Wasserstein SB: Children's predisaster functioning as a predictor of posttraumatic stress following hurricane Andrew. J Consult Clin Psychol 1998, 66(6):883-892.

62. Proctor LJ, Fauchier A, Oliver PH, Ramos MC, Rios MA, Margolin G: Family context and young children's responses to earthquake. J Child Psychol Psychiatry 2007, 48(9):941-949.

63. Asarnow J, Glynn S, Pynoos RS, Nahum J, Guthrie D, Cantwell DP, Franklin B: When the earth stops shaking: earthquake sequelae among children diagnosed for pre-earthquake psychopathology. I Am Acad Child Adolesc Psychiatry 1999, 38(8):1016-1023.

64. Foy DW, Madvig BT, Pynoos RS, Camilleri AJ: Etiologic factors in the development of posttraumatic stress disorder in children and adolescents. J Sch Psychol 1996, 34:133-145.

65. Weems CF, Pina AA, Costa NM, Watts SE, Taylor LK, Cannon MF: Predisaster trait anxiety and negative affect predict posttraumatic stress in youths after hurricane Katrina. J Consult Clin Psychol 2007, 75(1):154-159.

66. Hensley L, Varela RE: PTSD symptoms and somatic complaints following Hurricane Katrina: the roles of trait anxiety and anxiety sensitivity. J Clin Child Adolesc Psychol 2008, 37(3):542-552.

67. Wickrama KA, Kaspar V: Family context of mental health risk in Tsunami-exposed adolescents: findings from a pilot study in Sri Lanka. Soc Sci Med 2007, 64(3):713-723.

68. World Health Organization: Integrating mental health into primary care: a global perspective. Geneva: World Health Organization and World Organization of Family Doctors (Wonca); 2008.

69. Inter-Agency Standing Committee: IASC guidelines on mental health and psychosocial support in emergency settings. Geneva: Inter-Agency Standing Committee; 2007.

doi:10.1186/s12888-014-0270-3

Cite this article as: Feo et al:: Prevalence of psychiatric symptoms in children and adolescents one year after the 2009 L'Aquila earthquake. BMC Psychiatry 2014 14:270

\section{Submit your next manuscript to BioMed Central and take full advantage of:}

- Convenient online submission

- Thorough peer review

- No space constraints or color figure charges

- Immediate publication on acceptance

- Inclusion in PubMed, CAS, Scopus and Google Scholar

- Research which is freely available for redistribution 